\title{
LA TEOLOGÍA COMO DOGMA CURRICULAR Y EL INICIO DEL LAICISMO JURÍDICO EN LA UNIVERSIDAD DE GUADALAJARA
}

\author{
Armando Martínez Moya ${ }^{1}$ \\ Universidad de Guadalajara - México \\ UPN. GDL/ISIDM. SEJ. Jalisco \\ Grupo de investigación HISULA \\ mmarmando@gmail.com
}

Recepción: 04/04/2010

Evaluación: 16/12/2010

Aceptación: 22/06/2011

Artículo de Reflexión

\section{RESUMEN}

La fuerza del paradigma teológico en la Universidad Colonial de Guadalajara (1792-1821), se expresó curricularmente en todas las carreras establecidas entonces. Su noción sobre el saber, sobre el destino del individuo, sobre la sociedad, sobre el papel a jugar por los futuros egresados, estuvo entonces influida por la visión paradigmática, dogmática y corporativa que predominaba en la Nueva Galicia no obstante el desarrollo del proceso productivo y comercial de la región en los años recientes que exigía nuevas formas de concebir las relaciones sociales y las exigencias cotidianas, así como la expansión de nuevas formas ilustradas de conocimiento. Sin embargo, a partir de la lucha de independencia que reclamaba la decrepitud del modelo colonial y las reformas que en otros lugares se hacían de la educación universitaria, la universidad oscilaba entre defender su modelo de enseñanza pero también intentó irse adaptando a las nuevas circunstancias reformistas que impulsaba la ilustración. Pero no será sino hasta la consumación de

\footnotetext{
${ }^{1}$ Investigador del Departamento de Estudios de la Cultura Regional de la Universidad de Guadalajara. Profesor del Departamento de Historia. Doctor de Historia de la Universidad de Huelva España. Secretario de la Sociedad de Historia de la Educación Latinoamericana - SHELA. Profesor de la UPN e ISIDM - México integrante del grupo de investigación Historia y Prospectiva de la Universidad Latinoamericana- HISULA.
} 
la independencia cuando la universidad se verá obligada a cambiar. Estos cambios tendrán su efecto en la carrera civil de Derecho que romperá con el determinismo escolástico.

Palabras clave: Revista Historia de la Educación Latinoamericana, universidad, teología, derecho civil, régimen colonial, independencia, ayuntamiento.

\title{
THE THEOLOGY LIKE CURRICULAR DOGMA AND THE BEGINNING OF THE JURIDICAL LAITY IN THE UNIVERSITY OF GUADALAJARA
}

\author{
Armando Martínez Moya \\ Guadalajara University- México \\ UPN. GDL/ISIDM. SEJ. Jalisco \\ Research Group HISULA \\ mmarmando@gmail.com
}

\begin{abstract}
The force of the theological paradigm in the Colonial University of Guadalajara (1792-1821), it expressed in a curricular way in all the careers established at the time. Its idea about the knowledge, about the individual's destiny, about the society, about the role to play for future graduates; thus, it was influenced by the paradigmatic, dogmatic and corporate vision which was predominating in the Nueva Galicia, nevertheless the development of the productive and commercial process of the region in the recent years that it was required new ways of conceiving the social relations and the daily requirements, as well as the expansion of new erudite forms of knowledge. Nevertheless, from the fight of independence that was claiming the decrepitude of the colonial model and the reforms that in other places were done of the university education, the university was ranging the model of education defended but also it tried to be adapting to the new circumstances reformists that it was stimulating the illustration. But it will not be but up to the consummation of the independence when the university will meet obliged to change. These changes will have his effect in the civil career of Law that will break with the scholastic determinism.
\end{abstract}

Key words: Journal of Latin American Education History, university, teology, civil law, colonial regime, independence, city council. 


\title{
A TEOLOGIA COMO DOGMA CURRICULAR E O INICIO DO LAICISMO JURIDICO NA UNIVERSIDADE DE GUADALAJARA
}

\author{
Armando Martínez Moya \\ Universidade de Guadalajara- México \\ UPN. GDL/ISIDM. SEJ. Jalisco \\ Grupo de pesquisa HISULA \\ mmarmando@gmail.com
}

\section{RESUMO}

A força do paradigma teológico na Universidade Colonial de Guadalajara (1792-1821) expressou-se curricularmente em todas as carreiras estabelecidas de então. Sua noção sobre o saber, sobre o destino do indivíduo, sobre a sociedade, sobre o papel a ser exercido pelos futuros egressos, esteve então influenciada pela visão paradigmática, dogmática e corporativa que predominava em Nova Galicia apesar do desenvolvimento do processo produtivo e comercial da região nos anos recentes que exigiam novas formas de conceber as relações sociais e as exigências cotidianas, assim como a expansão de novas formas ilustradas de conhecimento. Todavia, a partir da luta de independência que reclamava a decrepitude do modelo colonial e as reformas que em outros lugares se faziam da educação universitária, a universidade oscilava entre defender seu modelo de ensino, mas também intentou ir-se adaptando às novas circunstâncias reformistas que impulsionava a ilustração. Porém não será sua sina até a consumação da independência quando a universidade se verá obrigada a mudar. Estas mudanças tiveram se efeito na carreira civil do Direito que romperá com o determinado determinismo escolástico.

Palavras-chave: Revista História da Educação Latino-americana, universidade, teologia, direito civil, regime colonial, independência, ajuntamento. 


\section{INTRODUCCIÓN}

Atenida a su modelo fundacional, la Real Universidad de Guadalajara incluía en su primer plan de estudios el Derecho civil -llamado con fines profesionales: Jurisprudencia- y el Derecho eclesiástico, llamado a su vez: Cánones, pilares del ordenamiento jurídico colonial. Junto a estos dos ámbitos de educación normativa, estaba la Teología y la Medicina, cuya preeminencia estaba marcada por su implicación en la salvación del hombre desde los planos físico y espiritual. Estas cuatro carreras constituían el paradigma imprescindible del saber, y por eso habían sido incluidas en el currículo universitario.

Sin embargo, en el transcurso de su vida académica estas carreras no corrieron parejas en orden e importancia. El carácter del modelo colonial, y los intereses y concepciones de las corporaciones que gobernaban la provincia y que tuvieron mayor incidencia en la universidad, propiciaron deliberadamente el despliegue de unas en detrimento de otras. Jugaron aquí también un papel importante las ideas y representaciones hegemónicas que el conjunto de la sociedad tenía en cuanto a su destino y de las expectativas tenidas en torno a lo que esperaban de los cuadros egresados de la educación superior.

Rastreando desde sus orígenes fundacionales, es posible descubrir que ciertos criterios que se privilegiaban como imprescindibles para justificar el establecimiento de la universidad, no tuvieron en realidad después ningún seguimiento ; no constituyeron una prioridad; se utilizaron solo con fines políticos. Fueron otros los intereses educativos y políticos utilizados. De ahí el apoyo a unas disciplinas de conocimiento a costa de otras.

\footnotetext{
${ }^{2}$ Una relación cuidadosa de la correspondencia, representaciones, peticiones, alegatos y múltiples documentos que emitieron las diferentes instituciones interesadas en la fundación de la Universidad durante casi un siglo, fue rescatada y publicada por Luis M. Rivera y publicada en la sección histórica de la Gaceta Municipal a partir de 1910. Ahí se muestran las múltiples argumentaciones y justificaciones que cada quien tenía para su establecimiento.

Una lectura en detalle del alegato centenario que se generó (1696-1791), revela determinadas prioridades que estaban ahí subsumidas, esperando el momento propicio para aflorar. Eran estas los verdaderos intereses y expectativas que existían por parte de instituciones como el Obispado, que fue quien acaparó finalmente las atribuciones en la conducción de la universidad. Están ahí, contenidas de manera implícita, entreveradas entre las argumentaciones explícitas ("el adelanto de la región, la preparación de cuadros, etc."), que se publicitaron para justificar el establecimiento de la universidad. Por ejemplo, el tipo de materias a impartir y quienes iban a ser sus titulares, las atribuciones del claustro y la forma de elegir a sus miembros, el vínculo de la universidad con la Iglesia, entre otras).
} 
Ya puesta en marcha (1792), la Universidad va a caminar dando una cobertura amplia a la carrera teológica, haciéndose efectivo de esa manera, un objetivo clave para la Iglesia que no estaba explicitado de manera prioritaria en las argumentaciones fundacionales. En realidad se trataba de proveer de cuadros eruditos a la Iglesia secular (Cabildo eclesiástico, obispados, dignatarios, claustro universitario, etc.) y al clero regular (órdenes religiosas, parroquias y capellanías).

\section{Elementos de la trama}

Pero a partir de la consumación de la independencia (1821), la tendencia se fue revertiendo, empezando a desarrollarse una atracción de las carreras desvinculadas de las esferas eclesiásticas. Esta reconversión no fue propiciada desde adentro, sino resultante de las expectativas políticas y profesionales externas, pues los rectores y el Claustro gobernante, tardaron buen tiempo en reconocer que la universidad tenía ya que rehacer sus fines y ejercicios profesionales. No concebían la decrepitud del modelo universitario, atenidos a que era una institución muy joven. Mantenerse en esa posición inamovible, propició lógicamente clausuras sucesivas durante la primera mitad del siglo XIX. La primera, en 1826, fue fulminante; al tomar posesión el primer gobierno federal de la provincia, la clausuró de inmediato por retrógrada.

Conforme a todo lo anterior, en esta entrega se intentará un seguimiento de dos carreras universitarias siguiendo su cobertura, situación escolar, implicaciones y finalmente su decadencia, o por el contrario su reanimación y despliegue, partiendo de un análisis elemental de lo que significaban como disciplina del conocimiento. Se trata de la dicotomía: Teología-Jurisprudencia pues constituye una muestra palpable de la diferencia paradigmática que representaban las dos carreras desde el punto de vista del conocimiento, pero particularmente como evidencia de la transición social, política y por consecuencia filosófica de Guadalajara entre 1792, -fecha del inicio de funciones de la universidad-, y 1860, año de su clausura definitiva, ya en plena época del liberalismo reformador.

El desenlace hará evidente que la Teología, -reina madre del saber y de las ciencias-, entrará en decadencia desde el punto de vista de las preferencias estudiantiles; y el Derecho laico, se fue convirtiendo en la disciplina de mayor influencia y vínculo con las sociedades decimonónicas de Guadalajara en la primera mitad del siglo XIX. 


\section{Muchos guiños al Rey}

La petición primera para fundar una universidad en Guadalajara tiene una intención francamente religiosa y clerical, el Obispo Felipe Galindo y Chávez, en 1699, al hacer la primera petición al rey; lo dice con todas sus letras: tengo pedido a su majestad se sirva de hacer real universidad y también be solicitado las bulas , para que ahí se leyese la doctrina de Santo Tomás y se confirieran grados, ofreciendo a sus expensas el sustento de colegiales... En su exposición, el Obispo Galindo no pierde de vista su argumentación regional, pero prioriza la misión religiosa, a saber: el fomento en que va el crédito del reino, el bien de sus bijos, el aumento de sujetos, el lustre de esta ciudad $y$ de todo el Obispado, el servicio y decencia de esta santa Iglesia y el fin de bien que esperamos creando en virtud, y letras sujetos para que se dediquen a bien del prójimo, y salud de las almas. La simbiosis universidad-religión es tan evidente, que dicho obispo al hacer la petición ofrece el recién fundado Seminario tridentino del Señor San José como la institución que podría convertirse en la universidad.

Se trataba particularmente de formar teólogos con un alto conocimiento de la religión y sus misterios. Pero también para poder sobrellevar los diferentes asuntos de la Iglesia en los más altos ámbitos del poder. Han reforzado esta estrategia los acuerdos del Concilio de Trento, orientados a volver a darle lustre a la Iglesia y detener el desprestigio respecto a la conducta y la preparación de los sacerdotes. Se requiere ahora formarlos a conciencia en las ciencias de la religión. Pero ¿por qué desde una universidad? porque tendría más privilegios que un Seminario diocesano, pues la provincia donde se asiente una universidad, es considerada una región con privilegio regio. De ahí que la Universidad tenía que estar al servicio pleno de la Iglesia. Pero el asunto no era tan instrumental; no se trataba solo de formar cuadros. Para finales del siglo XVII la Iglesia juega en la Nueva España un papel de poder amalgamado con el Estado. Comparte con él un poder equilibrado no obstante que lo haga a través de una disputa soterrada. Es en esta perspectiva -en cuanto a la simbiosis Estado-clero provincial-, en donde debemos situar la actuación del obispado y su apoyo decidido a la creación de una universidad.

\footnotetext{
${ }^{4}$ Revista Episcopal "Voz de Aliento", del 4 de marzo de 1911. Citado por DÁVILA GARIBI. José Ignacio. (1957): "Apuntes para la Historia de la Iglesia en Guadalajara”. Tomo II. México, Ed. Cultura, p. 744.

5 ÍGUINIZ, Juan B. (1959): “La Antigua Universidad de Guadalajara”. México, UNAM, p. 8.

DÁVILA GARIBI. José Ignacio. (1957): óp., cit, p. 185.
} 
Volvamos a los antecedentes fundacionales. Es hasta mediado del siglo XVIII, que se produce una segunda petición. Esta ya no parte de la Iglesia. Ahora es el Ayuntamiento de la ciudad quien retoma la batuta a través de un extenso escrito firmado por el regidor De la Mota Padilla. Poco se ha recapacitado sobre las razones de que haya sido precisamente esta corporación quien haya retomado el asunto 50 años después , lo cierto es que esta petición está ampliamente documentada. Se establecen ahí las causas regionales (geográficas, sociales, políticas y económicas), necesarias e imprescindibles para fundar una universidad.

La petición ha sido a través de la pluma del historiador y miembro del Cabildo del Ayuntamiento, Matías de la Mota Padilla; en un textopetición lúcido y documentado. Ahí es posible descubrir el carácter, la mentalidad que en ese tiempo tiene el cabildo de la ciudad. Este manifiesta una posición que sugiere un espíritu ilustrado, reformador. Parece vislumbrarse un imaginario: el gran sueño de promover el adelanto de la provincia hasta situarla en la cúspide de todas las demás. Buscar un adelanto ataviado de atributos modernos en todos los campos de la vida regional. Pero para impulsar ese proyecto se necesita necesariamente una casa de altos estudios: La universidad de Guadalajara.

La vieja idea de la provincia sumisa, de la ciudad-fortaleza cobijada de un monolitismo político colonial; de la ciudad atalaya pensada desde la visión del expansionismo diocesano, el núcleo de la evangelización y el control de la grey; de la ciudad concebida como escaparate para el lucimiento de las corporaciones, la grandeza de sus tradiciones, rituales y protocolos nobiliarios y el acatamiento de órdenes; la idea de una provincia surtidora de beneficios para la capital y la metrópoli. Esas ideas sobre la ciudad, sobre la provincia no son ya el referente principal del Cabildo. Cuando menos en este célebre alegato de 1750.

En el documento-petición de Mota Padilla, Universidad y región aparecen por primera vez como un binomio imprescindible. La región concebida como un espacio para la expansión productiva, para la circulación comercial, para hacer confluir a los habitantes de todas sus latitudes necesitados de dirimir judicialmente sus asuntos. Un ámbito para

\footnotetext{
${ }^{7}$ Un seguimiento sobre los asuntos, argumentaciones y acuerdos del Cabildo de la ciudad en los años cuarenta del siglo XVIII, podría dar luz sobre su carácter ilustrado o retardatario, y con ello entender si solo fue fruto de la lucidez de Mota Padilla o de todo el cuerpo de munícipes. En el trabajo que ahora hago sobre la historia del Cabildo de Guadalajara espero aportar algo al respecto.
} 
gestionar desde lo administrativo todo ramo necesario de sancionar. Ya no es una simple referencia geográfica, pues Guadalajara es entonces sede de los poderes públicos y un lugar para coincidir y dialogar; atenderse las enfermedades, hacer negocios, conseguir trabajo y por supuesto: para ilustrar a sus hijos. La universidad no tiene entonces solo un papel educativo que jugar; en la cosmovisión del Ayuntamiento, la Universidad vendría a ser una institución impulsora de las luces, para darle lustre y prestigio moderno a la ciudad y la región; para configurar y reproducir una elite experta en asuntos diversos: abogados, doctores, escribientes, administradores de rentas, religiosos doctos, notarios. Hay un ambiente de pujanza, de apertura. No es gratuito que sea la época de la instalación de nuevas corporaciones como: el Consulado, la Casa de Moneda. La misma Intendencia de Guadalajara, es resultado de una estrategia general para el cambio; es una cobertura para propiciar reformas.

La orientación profesional de las carreras puede deducirse de la función social que se supone debe asumir la universidad. Así, en el documento en cuestión, a nombre del Muy Ilustre Cabildo y Regimiento, Mota Padilla solicita en esta ciudad una universidad para que en ella estudien y se gradúen en todas las facultades los hijos de estos reinos y de más vasallos que vengas aquí. La expresión: "todas las facultades" implica ya un cambio con relación a la anterior petición claramente eclesiástica. También se distingue la caracterización de la función social que tendría la universidad respecto al tipo de profesiones que se consideran necesarias:

...si todos los hijos de estas poblaciones de estos Reinos vinieran a esta ciudad con mayor comodidad a estudiar que a la de México, si hubiera universidad general, en que pudieran elegir facultades según sus inclinaciones, y no vienen sino aquellos que se aplican al estudio eclesiástico y a quienes les basta la Teología Escolástica y Moral.

Nótese la expresión reduccionista que se aplica a los estudios teológicos: "les basta la teología"-, como diciendo: es lo más elemental. No es una expresión casual, más adelante cuando justifican la inserción de las 3 carreras civiles que complementa el currículo, dicen: si en esta

${ }^{8}$ Proposiciones formuladas por el Lic. Matías de la Mota Padilla, por acuerdo del Ayuntamiento el 13 de mayo de 1750, para solicitar al Gobernador de la Nueva Galicia, que apoyase la idea del establecimiento de universidad en la capital del reino (Doc. No. 285). En: Copia del expediente relativo a las gestiones hechas por el Ayuntamiento de Guadalajara en 1758 para fundar la Universidad en ella. Gaceta Municipal de Guadalajara. (1919). Tomo III.

Ibídem., p.189. 
ciudad se dieran grados y se cursaran las cátedras de Jurisprudencia y Medicina, no se malograrian tantos. Porque no ordenándose de nada les aprovecha el estudio de la teologia que es lo que pudieron estudiar ${ }^{10}$.

Esa expresión: “que es lo que pudieron estudiar", califica despectivamente a la Teología. Esto es sorprendente e inusual, si pensamos en el nivel que existía aún de monolitismo y disciplina institucional respecto al pensamiento religioso y la Iglesia en Guadalajara para mediados del siglo XVIII. Vemos que el Cabildo secular no puede entonces guardar las formas. Ciertas expresiones van delatando una apuesta más ilustrada y menos complaciente. Para no comprometerse y compensar esas expresiones reveladoras, hasta cierto punto divergente de la forma de pensar corporativa de la época, y para congraciarse ante la potestad eclesiástica, el Cabildo de la ciudad aborda el destino de quienes estudian teología al agregar que:

\section{Habiendo crecido el número de consumados teólogos, lo más} que pueden aspirar es a un beneficio de los de este Obispado, que por lo general son cortos y muy trabajosos, porque aunque se ballan suficientes para oponerse a una de las canonjías di esta y de otras iglesias, no salen de ellas por faltarles el grado .

La posición de los munícipes es amplia: una de sus preocupaciones es el estado de los ramos civiles, de ahí su insistencia en vincular la ciudad, la región y las condiciones institucionales a lo que la universidad pueda aportar. Por ello, al no estar en los parámetros del progreso el estudio de la Teología, no la considera como el culmen exclusivo del saber universitario, sino que éste es colocado al mismo nivel de otros saberes (e incluso menos, como hemos visto), junto con Cánones, Jurisprudencia y Medicina.

En cuanto a la Jurisprudencia como carrera y profesión, su inclusión reivindica la necesidad imperiosa de la formación de profesionales abocados a los múltiples asuntos que tradicionalmente atienden y a las nuevas responsabilidades que la ciudad y la Intendencia ofrecen, a saber: la administración de bienes y productos en el abasto y los que eran almacenados; la administración de la justicia criminal y civil -que eran tan abundantes-, las regulaciones y los pleitos mercantiles y de propiedad -y con ello los asuntos notariales-. La expansión demográfica, los límites de

\footnotetext{
${ }^{10}$ Ibídem., p.189.

Ibídem., p.189.
} 
las atribuciones legales, la enmarañada jerarquía y los asuntos derivados de la vida política, religiosa y productiva de Guadalajara y la Nueva Galicia. En fin, se requería sin duda de una pléyade de abogados diestros a dirimir y aplicar justicia en muy diferentes instituciones: en la Real Audiencia, en el Ayuntamiento, en la Albóndiga, en las Aduanas, en las corporaciones que iban aflorando, en fin, en viejas y nuevas instituciones. Esto está claramente asumido por el Cabildo de la ciudad en esta célebre petición de 1750 y en muchas más que ofrecerá durante casi medio siglo después.

En dicha petición, La Teología no fue exenta del currículo, sino como dijimos puesta (casi) al mismo nivel de las otras disciplinas. El Ayuntamiento la propone como carrera siempre y cuando la lectura de cátedras se trasladen: una del Colegio Seminario y las otras sean impartidas por un dominico, un franciscano y un jesuita, los estudios no difieren de los parámetros clásicos de los estudios escolásticos: Teología, Santo Tomás, "SutilEscoto" y Sagradas Escrituras. En una propuesta posterior, se propone que las cátedras sean solo impartidas por franciscanos ${ }^{12}$.

Para el caso de estudios de Jurisprudencia, en la propuesta de 1750 esta carrera se argumenta junto con la de Cánones. Su misión es la observancia recta de la ley, ya sea en el orden religioso como en el civil. Las cátedras deben ser impartidas por "prebendados y abogados doctores... que dediquen a leer una o dos cátedras de Cánones y Leyes. En 1775, el Cabildo propone dos cátedras de Derecho Civil, junto con una de Retórica" ${ }^{13}$.

A partir de 1750 las peticiones y respuestas se van a suceder interrumpidamente. En ella interviene la Audiencia, los Obispos en turno, el Ayuntamiento y el Rey. Sobresale como petición documentada y extensa la del Obispo Fray Antonio Alcalde, quien en 1772, insiste en la fundación. Su argumentación repite sin embargo lo dicho ya por el cabildo de la ciudad 22 años antes. Pone énfasis en las necesidades regionales y en conformación de abogados:

\footnotetext{
${ }_{13}^{12}$ Libro Capitular de 1776. Fojas 79 y vuelta. Rivera, óp., cit.

${ }^{13}$ Ibídem. La cátedra de Retórica en Nueva España, además de estar unida a la tradición curricular de la enseñanza cristiana, también lo estará muy fuertemente desde la universidad de México en el siglo XVII, al estudio de contenidos clásicos y profanos y tendió a convertirse en instrumento académico de lasa ciencias y las Artes. A partir del siglo XVIII se vinculará con la Abogacía a través de los textos de Quintiliano y Cicerón y el Derecho Romano. Cfr: OSORIO ROMERO, Ignacio. (1986): La enseñanza de la retórica en el siglo XVI novohispano. México, Investigación Humanística. N. 2. UAM, pp. 87-104. (La propuesta del Cabildo refrendada en 1788, incluye estudiar principalmente a Quintiliano).
} 
En adelanto de la juventudy de todas las provincias de su diócesis que por falta de Universidad se atrasan en los estudios y dejan de graduarse muchos de sus naturales (...) de lo que resulta que los tribunales de este distrito se hallen muy escasos de abogados que dirijan los negocios con acierto .

En lo concerniente a la carrera de Teología, Alcalde solicita se establezcan las cátedras de: Teología Escolástica, Teología Moral y Filosofía. Como estas 3 cátedras serían a costa de su traslado del Seminario y de las órdenes religiosas, el obispo hace una donación de 20 mil pesos para las carreras de Leyes y Cánones. Esta aportación fue determinante para destrabar los trámites, pues al poco tiempo llegó la autorización para la fundación. Resulta ahora paradójico que haya sido precisamente la Iglesia la que aportase directamente los fondos para la cátedra de jurisprudencia y no la Audiencia, o el Rey, o el mismo Ayuntamiento.

El año de 1788, un poco más de 90 años desde que se solicitó la universidad por primera vez y 30 desde que el Ayuntamiento hizo su primera petición, el Cabildo de la ciudad continúa insistiendo y refrenda la importancia tanto civil como religiosa para fundar las carreras universitarias solicitadas. Sus argumentos dibujan marcadamente un escenario propicio para el ejercicio de profesiones diversas: muy principalmente por el notable aumento de la población, vastos descubrimientos de tierras enemigas (y aún ignotas) de caudales, civilidady nueva erección de obispados y Ciudad de Arizpe, lo cual exige mayor número de personas instruidas así eclesiásticas como seglares... Aflora en esta nueva petición a Carlos IV, un espíritu más resueltamente moderno; resaltando la importancia que le otorgan al carácter productivo, aunque dicha petición sea calculadamente comedida, apelando a la benevolencia del monarca: No podemos dejar de admitir que un soberano tan magnánimo como el nuestro, esté erogando sumas inmensas de dinero en doblar (sic) estas provincias internas y adelantar en ellas la Religión, las Artes, los Plantios, las manufacturas ${ }^{16}$.

Es así como al replantear las cátedras propone incluir Filosofía Experimental, Latinidad, Retórica, Moral, Matemáticas Astrología, Historia, Cirugía, Lenguas y en el campo del Derecho: Derecho Público, Derecho Patrio,

\footnotetext{
${ }^{14}$ Informe rendido en 1772 al Rey por el ilustrísimo Don Fray Antonio Alcalde, obispo de la Nueva Galicia, en cumplimiento a lo dispuesto en la cédula que antecede (3 de Noviembre de 1774). Documento No. 293. Rivera, Luis M. Copia del expediente. Doc cit. Gaceta Municipal de Guadalajara. 1918.

${ }_{16}^{15}$ Memorial del Ayuntamiento enviado al Rey. 1788. Doc. 312. Copia del Exp.

Ibídem., p.190.
} 
tanto español como indiano. Las cátedras de Leyes de prima, sobre materias civiles lo dispuesto en el Digesto, Código, e Instituta. Incluso en los contenidos propuestos para Cánones, se propone el estudio del Derecho municipal ${ }^{8}$.

La inclusión de estas disciplinas y contenidos en el currículo de leyes, particularmente el Derecho Publico y Municipal, sienta nuevamente un antecedente clave para la historia de la enseñanza del derecho civil en Guadalajara, puesto que muestra el interés de cuestionar desde la potestad civil y las instituciones seglares indianas y provinciales la conducta y los conflictos de los pobladores. También muestra la importancia que intenta dársele ya a la Jurisprudencia en el campo de la tradición de los gobiernos de las ciudades. Toda esta propuesta para la universidad permite situar al Ayuntamiento y su Cabildo mirando hacia el porvenir.

En este célebre Memorial de 1788, los munícipes también plantean lo concerniente al estudio de la Teología; proponen ahí leer una teología positiva sacada de la escritura, Padres y Concilios (prima de Teología); leer la moral con arreglo a sentencias. Su propuesta es amplia, pero no está acompañada de la amplitud y pensamiento renovador como sí lo hizo para el Derecho Civil. Tres años después, en 1791 llegó la cédula que fundaba finalmente la universidad. Al año siguiente quedó establecida. Como hemos referido antes, ahí la historia de las carreras se escribió con criterios ajenos a todas estas argumentaciones.

\title{
La primavera de la Teología
}

\author{
En la sacra Teología, el blanco color demuestra \\ De su docta facultad, el candor y la pureza, \\ Quien tiene a Dios por objeto, \\ ¿Qué esplendor hay que no tenga?
}

Pedro Calderón de la Barca.

La Protestación de la Fe. 1656

Como paradigma doctrinal y como contenido de enseñanza la Teología estaba ya para finales del siglo XVIII en una profunda crisis y decadencia. Evolucionaba y se transformaba la sociedad y los estudios escolásticos seguían aferrados a mantener sus parámetros, influidos por la inercia de lo que constituyó como doctrina y acción desde el siglo XVI mexicano.

${ }_{18}^{17}$ Ibídem., p.191.

${ }^{18}$ "Leer Derecho Municipal sacado de las bulas de Indias, solitas de Obispos, Conciliosy Disciplina de América, encargando a esta facultad de la edición del Bulario Indiano, obras que hasta abora se desea". 
Como carrera universitaria, la Teología apareció al fundarse la Universidad de México en 1551. Su papel jugado como fuente de conocimiento y como recurso para explicarse la realidad mexicana fue fundamental. Tuvo, según Villar, una gran influencia en el desarrollo general de México. Junto al estudio del Derecho, argumentó, reivindicó y posibilitó actuar respecto a:

Losprincipios que reconocieron la racionalidad de los indios, el ejercicio de su libertad y autodeterminación; organizaron el régimen jurídico y politico durante tres siglos; contuvieron los excesos del poder; fijaron un marco de acción administrativa y crearon un régimen jurídico en el cual la supremacía del Derecho fue el eje de las relaciones entre gobernantes y gobernados. Si bien sirvió a los fines del Estado, también limitó sus abusos.

Habrá que entender que la contribución doctrinaria de la Teología a la institucionalización de la vida colonial, fue en el terreno de la argumentación retórica, de las disputas verbales, desarrolladas con un lenguaje indirecto, erudito; subliminal, diríamos ahora. Pero siempre manifiesto. No se sustenta en una posición contestataria y abiertamente contrastante, pues la tradición política española respecto a la relación entre Estado e Iglesia, se daba desde el mensaje cifrado, metafórico, entre la cortesía y el protocolo, las sentencias y las profecías. Aunque es importante resaltar que el recurso retórico de la Iglesia desde la enseñanza y toma de posición del discurso teológico, también significó la defensa pecuniaria de sus crecientes intereses e influencias; del desarrollo y reproducción de una elite y una estructura de poder espiritual y material.

Al fundarse la Universidad en 1792, según las Constituciones de Salamanca, que fueron las que se establecieron provisionalmente mientras se redactaron las propias, se establecían cinco cátedras de Teología, dos de ellas se trasladaron del Seminario Conciliar. Tres cátedras empezaron a ser leídas sin remuneración por religiosos regulares; los Mercedarios se responsabilizaron de la cátedra Lugares Teológicos . También participaron los Franciscanos y los Dominicos. Las materias que se empezaron a impartir en la universidad fueron: Prima de Teología, Santo Tomás, Teología y Lugares Teológicos y Sagrada Escritura.

${ }^{19}$ DE LA TORRE VILLAR, Ernesto. (1991): La Teología en Nueva España. Apuntamientos. México, Memorias de la Academia Mexicana de Historia. Tomo XXXIV, pp. 5-61.

${ }^{20}$ Constituciones de Salamanca adaptadas para la Universidad de Guadalajara. Cfr: ÍGUINIZ, Juan B. (1992): Catálogo Bibliográfico de los doctores licenciados y Maestros de la Antigua Universidad de Guadalajara. México, Ed. Universidad de Guadalajara. 
Pero para finales del siglo XVIII, precisamente en la época en que se establece la universidad, la Teología era una disciplina que estaba ya decrépita en cuanto a sus usos y fines universitarios. Incluso antes: al revisar las disertaciones que para el tiempo de la fundación se daban en la Universidad de México, los temas referidos a las disputas filosóficas en el terreno del dogma religioso, las argumentaciones sobre diversas problemáticas existenciales, fuesen de tipo escolástico o referido a problemas de las instituciones, las razas, el Estado, los valores o los sentimientos y pasiones habituales, habían desaparecido. Ahora los planteamientos eran por lo general estériles y a veces pusilánimes; se habían agotado los grandes temas o las preocupaciones de los alumnos y maestros estaban más en torno a otras disciplinas de conocimiento. Ahora se veían temas como saber sobre el color de la piel de Cristo, o la impresión que causan las naves catedralicias en la fe, o si la agitación de lidiar toros era lícita para el alma humana ${ }^{21}$.

Claro está que un nutrido cuerpo de doctores y alumnos de la Universidad de México y después de la de Guadalajara una vez fundada, abordaron rigurosos ejercicios reflexivos, con argumentos inclinados a despejar y debatir sobre diversos aspectos espirituales o científicos; temas relativos ya no solo al dogma, sino a la iglesia como institución perfectible, a los indios y su condición, al poder, entre otros tópicos. Pero el destino de la disciplina ya estaba marcado. Un pasado de inamovilidad conceptual centenaria pasaba la cuenta, pues, muchos de los ingentes asuntos de la vida política y espiritual de la Intendencia para fines del siglo XVIII, habían requerido desde mucho tiempo atrás, ser decantados, sopesados y ampliamente debatidos y resueltos. No se hizo en su momento. Ahora el destino alcanzaba a la Teología.

Aún así, al establecerse la Universidad, la carrera que mayor atracción tuvo y que por consiguientes copó la admisión, fue la de Teología (que como dijimos era la que más cátedras ofrecía al fundarse). Conjeturando sobre este fenómeno, podremos suponer que tuvo que ver esa influencia corporativa centenaria, aquella que seguía gravitando sobre la sociedad tapatía y que, una vez establecida la universidad, generó que los hijos de las familias más pudientes pensaran en ingresar a sus hijos en la carrera teológica. Esta expectativa escolástica es lógica y entendible, pues prevalecía fuertemente la idea de que el destino más seguro, más digno

${ }^{21}$ DE LA TORRE VILLAR, Ernesto. (1991): óp., cit, pp.55-56. 
y más remunerable para los jóvenes, era obtener un grado teológico que les permitiera hacer carrera en todas las altas jerarquías de la Iglesia.

\section{Los abogados y el derecho civil: trayectoria incipiente.}

Hay una tradición de largo aliento del Derecho y su ejercicio en la América Española. Desde los orígenes mismos de la conquista y colonización se requirió de un paradigma jurídico y directrices profesionales legales para resolver los múltiples problemas que se fueron suscitando: reclamos de sucesión, deslindes de propiedades y su legalización, herencias, matrimonios, puestos del cabildo, criterios para ventas de comercio, pagos de jornal, pleitos diversos, en fin, un sinnúmero de asuntos que se iban presentando abrumadoramente como producto de la expansión territorial y demográfica colonial. Pero la tradición jurídica castellana se remonta a épocas aún más pretéritas producto de sus propias vicisitudes como Reino. A diferencia de los teólogos, que tienen un origen institucional marcadamente religiosocorporativo, los abogados nacen como una profesión civil, muy vinculada al Estado. Ya una ley de la Corte española de 1617, relativa al "Examen y juramento de los abogados y su incorporación para poder abogar en la corte", establecía desde entonces:

los que de aqui en adelante trataren de abogar, antes que lo comiencen a usar, se examinen en el Colegio y asi los que abogaban antes de la pragmática, como los que en adelante trataren de abogar, juren todos en el Consejo para usar de los dichos oficios, $y$ todos los que fueren recibidos y aprobados por el consejo que no bubieren entrado en la congregación de los abogados se inscribany entre en ella dentro de ocho días de la dicha aprobación y pasados no lo babiendo hecho no pueden abogar en esta Corte, so pena de caer e incurrir en las penas de los que abogan sin licencia y al tiempo del examen o aprobación se les aperciba.

Además de que esta normativa muestra el intento de regularizar y profesionalizar a los abogados, así como de su utilización individual al servicio del poder político, se observa también su proliferación, al grado

\footnotetext{
${ }^{22}$ Ley Primero título 19 del libro IV de la Novísima Recopilación de las Leyes de España. 23 de noviembre de 1617. Biblioteca Nacional de Madrid. Los Colegios se usaban preferentemente para designar los establecimientos docentes donde se impartían los conocimientos propios de cada profesión. Después, en el período borbónico se fueron convirtiendo en órganos de asociación de profesionistas dedicados al ejercicio de una misma profesión.
} 
que existen muchos que litigan sin el título. Al rastrear en la historia de las profesiones en España, que es el antecedente idóneo para entender la profesión de la abogacía en las colonias, se puede observar la importancia del derecho en la sanción legal de las propiedades. En este sentido una de las primeras formas de organización profesional fueron los Notarios; que se convirtieron en especialistas en dar fe sobre determinados actos de representación personal y particularmente en otorgar posesiones legal en propiedades, que es un elemento clave respecto a una de las principales

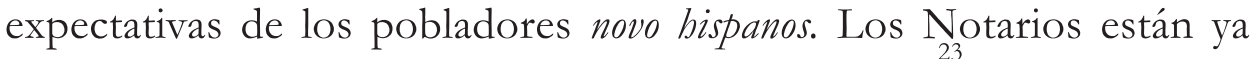
organizados desde época muy temprana en España ${ }^{23}$. En cuanto a la configuración del corpus jurídico español, sabemos que tiene influencia decisiva el Derecho Romano, por razones históricas. Es el referente más importante para legislar sobre el hombre común. Sin embargo, al ingresar como parte del currículo en las universidades medievales españolas, aparecerá subsumido al derecho religioso, al Corpus iuris canonici ambos constituirán el Derecho Común ${ }^{24}$.

Esa tradición integrista del derecho español se trasladó a la América española e incluso se expandió, cuando la realidad colonial impuso nuevas y diversificadas -y abigarradas- disposiciones que constituyeron las Leyes de Indias. Un abogado en los Reinos españoles ultramarinos debía entonces saber mucho de leyes españolas y bastante más de leyes indianas. De ahí que la Universidad de Guadalajara tenía inserto en su currículo el Derecho público, llamado simplemente "Leyes" o "Jurisprudencia" entendido como el ámbito de los asuntos civiles particulares y públicos. Parecía que con ello no tendrían las autoridades, los funcionarios y los vecinos de esta ciudad y sus alrededores, que continuar contratando licenciados hasta la capital del virreinato o importarlos de España para cubrir las necesidades jurídicas públicas y privadas. La nueva carrera lo evitaría, pero no fue así, cuando menos al principio. Lo más probable es que los antiguos criterios de reclutamiento de abogados continuaran durante un buen tiempo, pues la matrícula a la carrera no fue muy

\footnotetext{
23 "La organización notarial alcanzó pleno desarrollo en Cataluña, en Aragón y en Valencia, donde al amparo de los fueros y privilegios de que gozaban estos reinos se dictaron disposiciones que aseguraron la autonomía corporativa de los colegios y la diferenciación de las funciones notariales. MORENO, Manuel M. “La Colegiación Profesional en México”. S/E. México. 1960. Pág. 10. LLAMOSAS, Esteban F. (2000): Presencia del Derecho Común en la Biblioteca Antigua de la Compañía de Jesús de Córdoba del Tucumán”, en La Biblioteca Jesuítica de la Universidad Nacional de Córdoba. ASPELL, Marcela; PAGE, Carlos A. República Argentina, UCN.
} 
significativa entre 1792 y 1815, como hemos dicho ya; la Teología se convirtió de inmediato en la carrera preferida de los educandos en los primeros años. Está también el hecho de que al fundarse la Universidad solo se estableció una cátedra de Derecho, a diferencia de Teología que estableció cinco. En la configuración curricular de la carrera es donde podemos ver la visión tan minimizada que se tenía de ella, pues para solventar los cursos requeridles para la carrera no se pensó en un principio aumentar el número de cursos, sino hecho mano a los de la carrera de Cánones, que eran considerados similares a los de Derecho. Vemos así el sometimiento que en términos académicos tiene ejercida la iglesia sobre la Universidad, pues no les cabe duda a las autoridades que un buen abogado es aquel que sabe bastante sobre derecho canónico.

El curso de Leyes era el llamado Instituta, donde se estudiaban las instituciones, su misión, sus leyes y sus problemas. Además de ver a los autores clásicos en esta materia, se veía también el Derecho Real de Castilla y Municipal de Indias y las reales cédulas sobre la materia que les explicaban ${ }^{25}$. Con el tiempo, esta carrera se fue haciendo más práctica y más acorde con las necesidades y litigios en boga.

\section{Auge y ocaso de la Teología, precariedad y contundencia del Derecho Civil}

Un seguimiento de la matrícula ${ }^{26}$ y la obtención de grados ayudan a conocer el camino recorrido por ambas carreras. Según los libros de asientos hasta la consumación de la independencia (1792-1821) se matricularon en todas las facultades 1,043 alumnos correspondientes a las 4 carreras $^{27}$. La de Teología registra 317 educandos y la de Leyes $214^{28}$.

\footnotetext{
${ }^{25}$ Constitución LIX de la Real Universidad de Guadalajara.

${ }^{26}$ Toda la información estadística está tomada de los libros de matrícula de asientos de la Real Universidad de Guadalajara, en su respectivo Archivo. Los expedientes consultados fueron 17: del 14 al 30, que contienen información de todas las carreras. Cuando entonces los consulté estaban en la Colección de Fondos Especiales de la Biblioteca Pública del Estado. Ahora se encuentran reubicados en el Archivo Histórico de la Universidad de Guadalajara. Casa Zuno.

CASTAÑEDA, Carmen. (1984): que ha trabajado con dedicación sobre este terreno en la universidad de Guadalajara, apunta que fueron 1,051 estudiantes; de los cuales 321 se matricularon en Teología, 408 en Cánones, 218 en Leyes y 104 en Medicina. "La Educación en Guadalajara durante la Colonia. 1552-1821". México, El Colegio de México, pp. 365-366.

${ }^{28}$ Es interesante ver que la carrera de Cánones fue la que más alumnos atrajo a sus aulas, con 408 inscritos. Medicina tuvo por su parte un total de 104. Como herencia persistente, la influencia religiosa en la región se ve plasmada en la Carrera de Cánones, que se mantuvo estable en su matrícula. Para C. Castañeda, esa persistencia tiene que ver con que las posibilidades de obtener un trabajo: pues tener un grado de Cánones daba más oportunidad de empleo que un grado de Teología.
} 
Teología. Esta carrera tuvo desde un principio un elevado número de alumnos matriculados que fueron ganando sus cursos respectivos. Nunca tuvo menos de 30 desde que se ofreció el grado por primera vez en 1792, hasta 1810 que disminuye drásticamente a 9 matriculados. Como bien muestra la historiadora Carmen Castañeda, la matrícula tuvo un ascenso vertiginoso entre 1792 y 1797 , que pasó de 28 alumnos registrados al inaugurarse las cátedras, hasta 75 alumnos casi al finalizar el siglo XVIII. Pero a partir de entonces la carrera empezó a declinar. La Doctora Castañeda lo atribuye a que los cursos de Teología del Colegio Seminario Tridentino se habilitaron para que los estudiantes pudieran graduarse en la Universidad de México y en la de Guadalajara.

Esa fue una razón poderosa, pero seguramente que hubo también otras razones determinantes. No olvidemos además que lo que precisamente querían evitar los padres de los estudiantes de Guadalajara, es tener que trasladarse a la ciudad de México a que se graduasen sus hijos por todo lo que implicaba el viaje en trámites y gastos. De ahí el fundar una universidad local. Además de ello, al revisar cuantos graduados de Teología hubo en la Universidad de Guadalajara a partir de 1798, -que es cuando se da esa disposición-, los cuales tuviesen como antecedente haber estudiado en el Seminario u otra institución foránea, resulta que el número en ínfimo, pues solo fue posible encontrar a siete entre ese año y 1820.

Es importante por lo tanto confrontar los índices de matrícula, los respectivos currículos de los alumnos y luego el proceso para la obtención del grado para que al cruzar la información, puedan observarse algunas situaciones realmente significativas respecto a ese problema de la declinación de la Teología, como esa de ver si el estudiar en otra institución implicó una baja en la matrícula.

Aunque hay un único ascenso en la matrícula en 1806-1807,-que de 28 en 1805 sube a 36 y 38 alumnos-, lo cierto es que la tendencia descendente no se va a detener después. Tener 38 alumnos inscritos en 1807 va a ser la históricamente la última cifra "alta" de la Carrera.

El inicio de la lucha insurgente va a pesar también sobre el comportamiento de la matrícula. En 1810 se inscriben sólo 10, cuando solo 3 años antes se habían matriculado los 38 alumnos ya referidos.

${ }^{29}$ CASTAÑEDA, Carmen. (1984): óp., cit, p. 36. 
En 1812 y 1813, solo se matriculan 4 alumnos y hay un ligero ascenso cuando se logra una cierta estabilidad en el reino una vez que se logró contener la agitación revolucionaria. Y aunque a todas las demás carreras también les afectó la lucha de independencia, sin embargo, la Teología no será ya nunca más la madre de todas las carreras. A partir de 1820, la recuperación de la matrícula a lo que más llega es a 12 alumnos.

Creo que es necesario explicarnos también esta situación atendiendo también las circunstancias y acontecimientos del contexto. En 1821 se consuma la independencia y esto implica un nuevo panorama aunque como sabemos, la independencia estaba originalmente pensada para lograr la continuidad de privilegios y el estatus existente. De ahí que la universidad se mantuvo sin cambios en su currículo y en su estructura. Seguramente que esto fue un grave error. Debió haberse planteado de inmediato una reforma para ponerse a tono con los nuevos cambios políticos y sociales ${ }^{30}$.

Entre 1821 y 1826, que es el período donde se hace llamar Nacional Universidad de Guadalajara, -(si bien cambia su denominación de Real por el de Nacional, sin embargo conserva toda su estructura regia y su modelo pedagógico dogmático fundacional)-, la matrícula es casi nula, llegando a tener cero matriculados en 1824, cuando se jura la Primera Constitución Federal Mexicana.

Respecto a los graduados las evidencias marcan una tendencia propia. Para empezar habrá que decir que el número de graduados es muy bajo con relación a la matrícula ${ }^{31}$. Solo se graduaron de 1793 a 1821: 44 Doctores en Teología (de un total de 317 matriculados). Para 1823 -año en que se registra el último graduado antes de la clausura de la Universidad-, son 46 los teólogos que obtienen el grado, es decir solo dos más ${ }^{32}$.

${ }^{30}$ Cuando en 1835 toma el poder la fracción unitaria y por tanto más conservadora del país, y por lo tanto la Universidad se restablece (pues fue suprimida en 1826), entonces es cuando se lleva a cabo su primera reforma, atendiendo a las directrices del religioso carmelita ilustrado Fray Crisóstomo Nájera).

Hace falta incluir en esta comparación la trayectoria estudiantil para verificar si efectivamente todos los matriculados concluían la carrera. Pues comparar a los admitidos con los egresados puede arrojar estimaciones erróneas.

${ }^{32}$ TOSCANO, Juan Carlos. "Relación estadística y comentarios de los alumnos que recibieron grados mayores de Teología, en diferentes etapas. 1793-1854.” Documento inédito elaborado a partir de los libros de matrícula de la Real Universidad de Guadalajara. Archivo de Historia de la Educación del DECR. U de G. Del total de graduados registrados (1793-1855) 65 hicieron sus estudios en la propia universidad y 10 en la de México. En total hubo entonces 75 graduados. Estos datos no coinciden con los de Carmen Castañeda, que reporta 66 doctores graduados. 
Derecho Civil: La carrera de Leyes por el contrario empezó con una matrícula muy caprichosa, de altas y bajas y luego ascendió. Entre 1792 a 1805 asistió un promedio de 13 alumnos por año, más bajo que Teología y Cánones y solo más alto que Medicina. Hubo un breve auge en 1808, cuando de manera inusitada se matricularon 40 alumnos, pero luego bajó drásticamente el porcentaje hasta situarse en un promedio de 8 alumnos por año. El año del desplome fue 1810 precisamente, año del inicio de la lucha de independencia. Sobresale en este período precario, la inscripción de solo dos alumnos en 1804 y dos en 1817, estos son los récords más bajos de la carrera.

Pero a partir de 1818, el ascenso de la carrera será vertiginoso, incrementándose la matrícula en los últimos años de su primer período de existencia hasta antes de la primera clausura de la Universidad en 1826 en el inicio del primer gobierno federal. Entre 1820 y 1826 la inscripción va in creciendo, en 1821 son 14 los matriculados; en 1823 el número sube a 20 y en 1826, a punto de cerrarse, son ya 31 alumnos quienes aspiran ser abogados. Los años claves de la transición del régimen colonial al independiente muestran ya una clara tendencia hacia la carrera jurídica civil.

En cuanto a los graduados de Leyes, el número es casi totalmente escaso. La consumación de la independencia se consumó en 1821 y en ese mismo año solo fue posible detectar 7 doctores que obtuvieron el grado. Esto confirma lo que se comentó líneas arriba en cuanto a que la inmensa mayoría de abogados, ejercían el oficio sin haberse titulado. La demanda de abogados era seguramente alta y también en las instituciones por lo que seguramente no les importaba solicitarles la certificación de que se hubiesen graduado. Tampoco existía una normativa a ese respecto.

\section{Los cauces toman su nivel}

Tomados literalmente los números son engañosos y caprichosos. Por ello no basta el recuento de matrícula y grados obtenidos. Hubo muchas situaciones que bajo el telón se suscitaron y que desbrozaron un itinerario que debemos entender más complejo. Un asunto es la sede de la carrera de Teología, que aunque seguía siendo una carrera de la universidad, en realidad empezó a impartirse en el Seminario Tridentino en los últimos años del período (1816-1826). Es decir las cátedras se trasladaron fuera de la Universidad. ¿Qué significaba esto? Seguramente que la Teología se empieza a concebir como una carrera eminentemente 


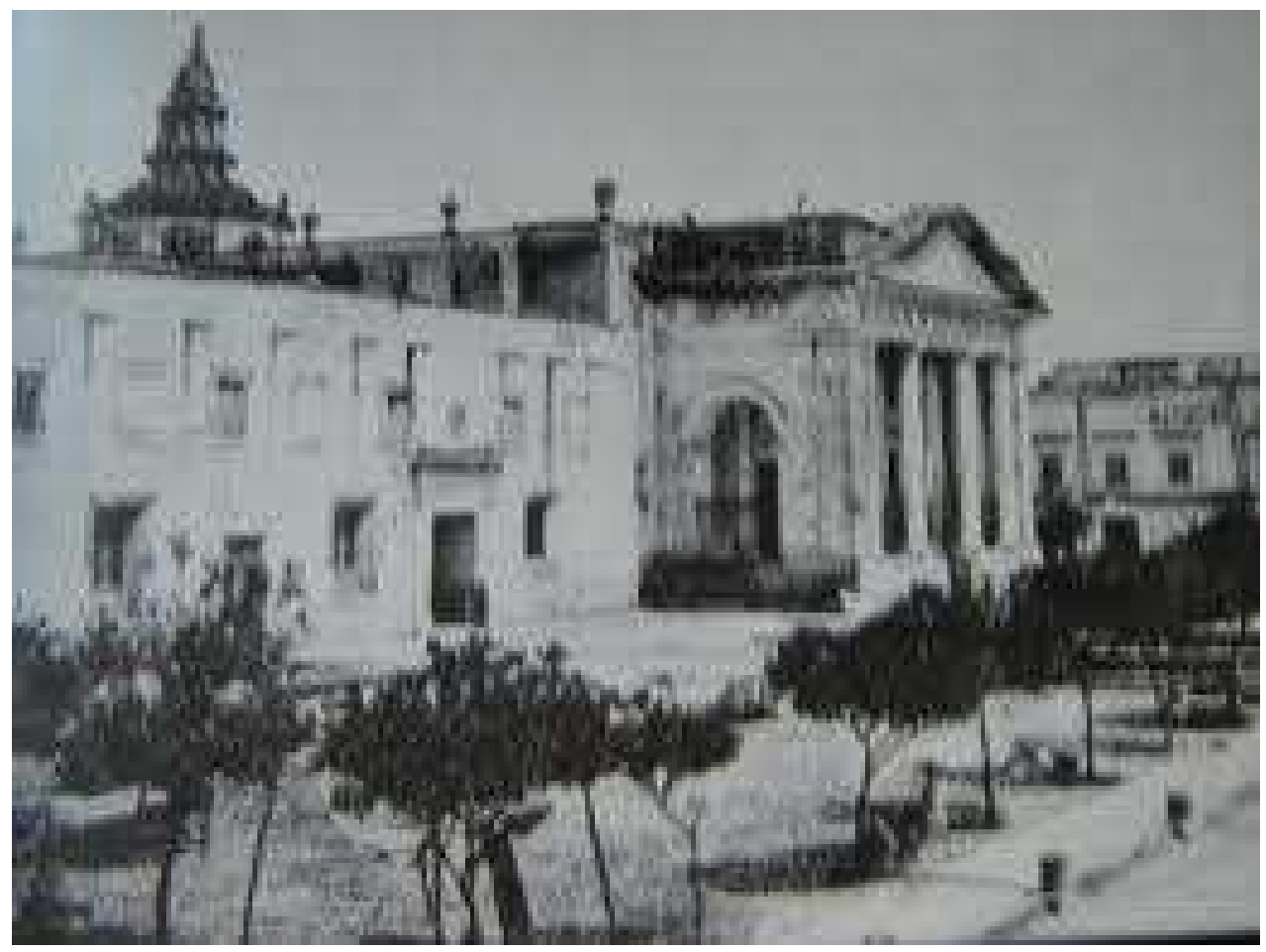

Unviersidad de Guadalajara - México

clerical, ya no como esa esfera universitaria de filosófica docta, necesaria para eminencias y dignidades destinadas a dirigir la superestructura de las diócesis.

Una lectura desde la esfera política también nos puede arrojar algunas interpretaciones. La consumación de la Independencia inauguró también la ofensiva contra el poder eclesiástico mexicano. Guadalajara era sede de uno de los obispados más grandes territorialmente y muy influyente. Demográficamente se concentraba en esa diócesis un número de personas que correspondía a cerca del 18\% de la población nacional. No debemos además, descartar el hecho de que la jerarquía eclesiástica tapatía fue una de las más vehementes y belicosas contra los insurgentes y los sectores liberales. La clausura fulminante de la Universidad como una de las primeras medidas del primer gobierno liberal en 1826, es muestra de la animadversión que se había ido gestando años atrás en contra de la Iglesia. La Universidad era un bastión de ella, y las carreras de tinte religioso también.

A contrapelo, Guadalajara había producido también una generación de pensadores radicales, pero no del bando eclesiástico, sino del liberal. 
De ahí la posición de Valentín Gómez Farías oriundo de la región y de toda la primera generación de ideólogos tapatíos que establecieron las primeras reformas políticas en la naciente nación, como el primer gobernador constitucional Prisciliano Sánchez que clausuró la universidad e inauguró el Instituto de Ciencias en 1827 en Guadalajara.

\section{CONCLUSIÓN}

De todo ello podría deducirse que hay ya un caldo de cultivo amenazante para los proyectos eclesiásticos. Uno de ellos era el educativo, y desde luego la carrera de Teología que era el atalaya ideológico, el paradigma de formación de cuadros defensores de los privilegios eclesiásticos. Fue uno de los componentes religiosos que los liberales consideraron necesario desterrar, cuando menos de la educación gubernamental. Por el contrario, los nuevos profesionales preparados para el foro, para la conducción laica de los asuntos legales de gobierno, para el deslinde jurídico de las grandes reformas de la propiedad desamortizada y la propiedad individual: significó dar cobertura a los abogados. Ellos eran ahora una necesidad imprescindible; lo que explica su ascenso y protagonismo desde entonces, en parte, a costa del ocaso de la carrera teológica.

Al cerrarse la Universidad en 1826 y abrirse el Instituto del Estado el año siguiente, se estableció el segunda currículo de educación superior en Guadalajara, pero ahora con un tinte laico y cientificista. El destino de las dos carreras aludidas tiene aquí un deslinde claro a favor de Leyes. Las secciones académicas que establece del Instituto no incluyen por supuesto a la Teología y sí al estudio del Derecho. Se plantea desde entonces dar Derecho Natural, Político, civil constitucional, general y del Estado. El Derecho Eclesiástico se aborda en una sola sección, dándosele un toque histórico, más que una connotación de disciplina necesaria.

¿Eran esas materias del Derecho, establecidas en el Instituto una verdadera novedad y producto de nuevas formas de interpretación jurídica? Para la Universidad de Guadalajara sí, pero como nuevo paradigma en el estudio del Derecho no. Esas disciplinas eran ya recurrentes cuando menos un siglo atrás. La universidad de Guadalajara, nacida con la virtud de ser contemporánea de las reformas borbónicas, no tuvo por desgracia tiempo suficiente para hacer cambios en ese primer período de ejercicio. 


\section{FUENTES}

Archivo Histórico de la Universidad de Guadalajara.

Archivo de Historia de la Educación del DECR. Universidad de Guadalajara.

Constitución LIX de la Real Universidad de Guadalajara

Gaceta Municipal de Guadalajara. 1918.

Gaceta Municipal de Guadalajara. 1919. Tomo III.

Informe rendido en 1772 al Rey por el ilustrísimo Don Fray Antonio

Ley primero título 19 del libro IV de la Novísima Recopilación de las Leyes de España. 23 de noviembre de 1617

Libro Capitular de 1776. Fojas 79 y vuelta.

Memorial del Ayuntamiento enviado al Rey. 1788. Doc. 312.

\section{REFERENCIAS}

CASTANEDA, Carmen. (1984): La Educación en Guadalajara durante la Colonia. 1552-1821. México, El Colegio de México.

DÁVILA GARIBI. José Ignacio. (1957): Apuntes para la Historia de la Iglesia en Guadalajara. México, Ed. Cultura.

DE LA TORRE VILLAR, Ernesto. (1991): La Teologia en Nueva España. Apuntamientos. Memorias de la Academia Mexicana de Historia. Tomo XXXIV. México.

IGUINIZ, Juan B. (1959): La Antigua Universidad de Guadalajara. México, UNAM.

IGUINIZ, Juan B. (1992): Catálogo Bibliográfico de los doctores licenciados y Maestros de la Antigua Universidad de Guadalajara. Guadalajara, Ed. U. de G. 
MORENO, Manuel. (1960): La Colegiación Profesional en México. México, S/E.

Revista Episcopal Voz de Aliento, del 4 de marzo de 1911.

OSORIO ROMERO, Ignacio. (1986): La enseñanza de la retórica en el siglo XVI novohispano. México, Investigación Humanística. N. 2. UAM.

TOSCANO, Juan Carlos. (1793): Relación estadística y comentarios de los alumnos que recibieron grados mayores de Teología, en diferentes etapas. 1793-1854. Documento inédito elaborado a partir de los libros de matrícula de la Real Universidad de Guadalajara. Archivo de Historia de la Educación del DECR. Universidad de Guadalajara. Del total de grduados registrados.

MARTÍNEZ MOYA, Armando. (2011): "La teología como dogma curricular y el inicio del laicismo jurídico en la Universidad de Guadalajara" en: Revista Historia de la Educación Latinoamericana N. 16, Tunja, Universidad Pedagógica y Tecnológica de Colombia, RUDECOLOMBIA, SHELA- HISULA pp. 151-174 